\title{
Graphical presentation of the power of energy losses and power developed in the elements of hydrostatic drive and control system
}

\author{
Part I \\ Rotational hydraulic motor speed series throttling control systems
}

Zygmunt Paszota, Prof.

Gdansk University of Technology

\section{ABSTRACT}

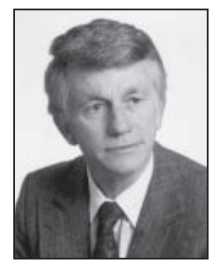

Paper proposes and justifies a diagram of the direction of increase of power stream from the shaft or piston rod of a hydraulic motor to the pump shaft, power increasing as an effect of the imposed power of energy losses in the hydrostatic drive and control system elements. Graphical interpretation of the power of energy losses in the hydrostatic drive and control system elements and also of the power developed by those elements is presented. An individual system with the rotational hydraulic motor speed series throttling control fed by a constant capacity pump cooperating with an overflow valve in a constant pressure system $p=c t e \approx p n$ is analyzed and also an individual system with the rotational hydraulic motor speed series throttling control fed by a constant capacity pump cooperating with an overflow valve controlled in a variable pressure system: $p=v a r$, an individual system with the rotational hydraulic motor speed series throttling control fed by a variable capacity pump cooperating with a pressure regulator in a constant pressure system $p=$ cte $\approx$ pn and an individual system with the rotational hydraulic motor speed series throttling control fed by a variable capacity pump cooperating with the Load Sensing regulator in a variable pressure $p=$ var system.

Keywords: hydrostatic drive and control system, power of energy losses, energy efficiency

\section{INTRODUCTION}

The graphic presentation, by means of fields with specific areas, of the power of energy losses generated in the elements of a hydrostatic drive and control system and of power processed in the hydraulic displacement machines used in the system, becomes a tool facilitating comparison of the size of losses.
Fig. 1 presents (as an example of a system with the hydraulic motor speed series throttling control fed by a constant capacity pump cooperating with an overflow valve) a diagram of the direction of increase of power stream from the shaft or piston rod of a hydraulic motor to the pump shaft, power increasing as an effect of the imposed power of energy losses in the hydrostatic drive and control elements.

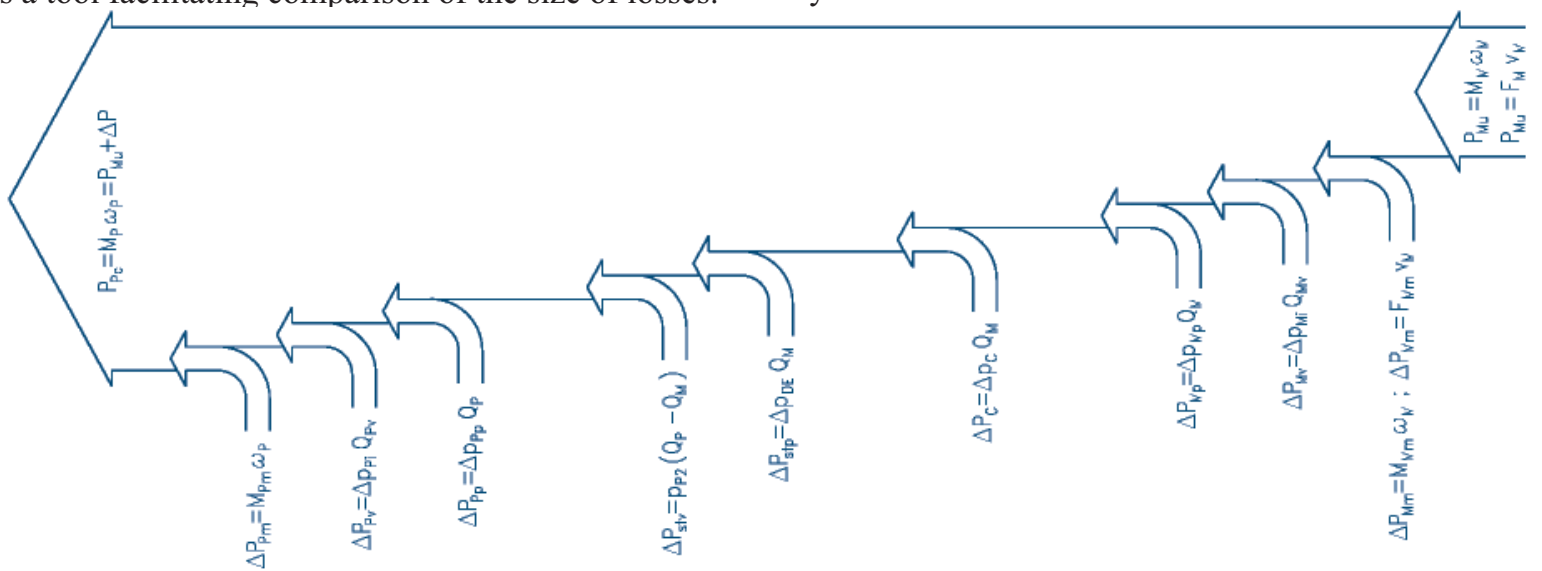

Fig. 1. The diagram presenting the direction of increase of power stream from the useful power $P_{M u}$ on the shaft or piston rod of the hydraulic motor to the power $P_{P C}$ consumed on the pump shaft as an effect of the power of losses generated in the hydrostatic drive and control system elements. Power $P_{P C}$ on the pump shaft is a function (a sum) of the power $P_{M u}$ on the shaft or piston rod of the hydraulic motor and the sum $\Delta P$ of power of losses in the elements (example of a system with the hydraulic motor speed series throttling control fed by a constant capacity pump cooperating with an overflow valve) $P_{M u}=M_{M} \omega_{M}-$ motor

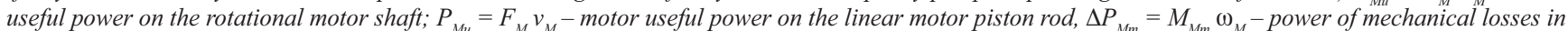
the rotational motor, $\Delta P_{M m}=F_{M m} v_{M}$-power of mechanical losses in the linear motor, $\Delta P_{M v}=\Delta p_{M i} Q_{M v}-$ power of volumetric losses in the motor, $\Delta P_{M p}=\Delta p_{M p}$ $Q_{M}$ - power of pressure losses in the motor, $\Delta P_{C}=\Delta p_{C} Q_{M}$ - power of pressure losses in the system conduits, $\Delta P_{\text {stp }}=\Delta p_{D E} Q_{M}-$ power of structural pressure losses in the throttling control assembly (in servo-valve, directional proportional valve, set throttling valve or set two - way flow regulator), $\Delta P_{s t v}=p_{S P}\left(Q_{P}-Q_{M}\right.$ ) - power of structural volumetric losses in the throttling control assembly (in overflow valve), $\Delta P_{P p}=\Delta p_{P p} Q_{P}-$ power of pressure losses in the pump, $\Delta P_{P v}=$ $\Delta p_{P i} Q_{P v}$-power of volumetric losses in the pump, $\Delta P_{P m}=M_{P m} \omega_{P}$-power of mechanical losses in the pump, $P_{P c}=M_{P} \omega_{P}-$ power consumed on the pump shaft 
The useful power $\mathrm{P}_{\mathrm{Mu}}=\mathrm{M}_{\mathrm{M}} \omega_{\mathrm{M}}$ determined on the rotational hydraulic motor shaft or $\mathrm{P}_{\mathrm{Mu}}=\mathrm{F}_{\mathrm{M}} \mathrm{v}_{\mathrm{M}}$ determined on the linear hydraulic motor piston rod, changing in the work field $(0 \leq$ $\leq \mathrm{M}_{\mathrm{M}} \leq \mathrm{M}_{\mathrm{M} \max }$ and $\left.0 \leq \omega_{\mathrm{M}} \leq \omega_{\mathrm{M} \max }\right)$ or $\left(0 \leq \mathrm{F}_{\mathrm{M}} \leq \mathrm{F}_{\mathrm{M} \max }\right.$ and $0 \leq \mathrm{v}_{\mathrm{M}} \leq$ $\leq \mathrm{v}_{\mathrm{Mmax}}$ ) of the motor driven device, is a result of instantaneous requirements of the device toward motor both as regards load $\mathrm{M}_{\mathrm{M}}\left(\mathrm{F}_{\mathrm{M}}\right)$ and speed $\omega_{\mathrm{M}}\left(\mathrm{v}_{\mathrm{M}}\right)$. Therefore, the instantaneous useful power $\mathrm{P}_{\mathrm{Mu}}$ is independent of the structure of hydraulic system (used for changing the motor speed $\omega_{M}\left(v_{M}\right)$ ) and of the power $\Delta \mathrm{P}$ of losses in the system elements. However, this does not apply to the upper limits of the device parameter ranges, i.e. maximum load $\mathrm{M}_{\mathrm{M} \max }\left(\mathrm{F}_{\mathrm{Mmax}}\right)$ and maximum speed $\omega_{\text {Mmax }}\left(\mathrm{v}_{\text {Mmax }}\right)$.

The upper limits of work field, determined by the $\mathrm{M}_{\mathrm{Mmx}}=$ $=\mathrm{f}\left(\omega_{\mathrm{M}}\right)$ and $\omega_{\mathrm{M} \max }=\mathrm{f}\left(\mathrm{M}_{\mathrm{M}}\right)$ or $\mathrm{F}_{\mathrm{M} \max }=\mathrm{f}\left(\mathrm{v}_{\mathrm{M}}\right)$ and $\mathrm{v}_{\mathrm{M} \max }=\mathrm{f}_{\left(\mathrm{F}_{\mathrm{M}}\right)}$ lines, of the hydraulic motor driving the device, depend on the theoretical capacity $\mathrm{Q}_{\mathrm{pt}}$ of the pump in the system, on the nominal pressure $p_{n}$ level of the system operation (the product $\mathrm{Q}_{\mathrm{Pt}} \mathrm{p}_{\mathrm{n}}$ is the reference power), on the motor speed control structure used, and also on the sum $\Delta \mathrm{P}$ of power of losses in the system elements. The upper limits of the motor work field differ in systems with different motor speed control structures.

On the other hand, the instantaneous power $\mathrm{P}_{\mathrm{Pc}}=\mathrm{M}_{\mathrm{p}} \omega_{\mathrm{P}}$ absorbed (consumed) by the pump from the drive (electric, internal combustion) motor, determined on the pump shaft, is a sum of the instantaneous useful power $\mathrm{P}_{\mathrm{Mu}}$ of the hydraulic motor and instantaneous sum $\Delta \mathrm{P}$ of power of losses in the hydraulic system elements: $\mathrm{P}_{\mathrm{Pc}}=\mathrm{P}_{\mathrm{Mu}}+\Delta \mathrm{P}$.

Power $\mathrm{P}_{\mathrm{Pc}}$ on the pump shaft is equal to the sum $\Delta \mathrm{P}$ of power of energy losses in the system elements $\left(\mathrm{P}_{\mathrm{Pc}_{\mathrm{c}}}=\Delta \mathrm{P}\right)$ during the operation with unloaded motor (when $\mathrm{M}_{\mathrm{M}}=0$ or $\mathrm{F}_{\mathrm{M}}=0$ ) or with the stopped motor (when $\omega_{\mathrm{M}}=0$ or $\mathrm{v}_{\mathrm{M}}=0$ ). The useful power $\mathrm{P}_{\mathrm{Mu}}$ of the motor and energy efficiency $\eta$ of the system are then equal to zero $\left(\mathrm{P}_{\mathrm{Mu}}=0, \eta=0\right)$. The information on the level of power $\mathrm{P}_{\mathrm{P}_{\mathrm{c}}}$ absorbed then by the pump and entirely lost in the system is particularly important at the system operation with unloaded motor (when $\mathrm{M}_{\mathrm{M}}=0$ or $\mathrm{F}_{\mathrm{M}}=0$ ). Power $\mathrm{P}_{\mathrm{Pc}_{\mathrm{c}}}$ of the pump operating with hydraulic motor stopped (when $\omega_{\mathrm{M}}=$ $=0$ or $\mathrm{v}_{\mathrm{M}}=0$ ) may be minimized by simultaneous cutting of the pump discharge conduit from the hydraulic motor and connecting this conduit with the tank, i.e. unloading the pump. However, this is only possible in an individual system, when the pump feeds only one hydraulic motor.

In references $[1-6]$ and other dealing with energy aspects of the hydrostatic transmission operation a need is discussed of determining the energy efficiency of those transmissions in terms of the power of the mechanical, volumetric and pressure losses in them.

In references [7 - 10] an approach is presented to the problems of energy losses in the hydrostatic drive system elements. It has been concluded, that the often practiced method of presenting the energy losses as a function of parameters depending on those losses should be abandoned.

Reference [10] ends with the following conclusions:

淡 the energy losses in the elements and also power of those losses should be presented as a function of parameters independent of those losses

* definition of the efficiency of system elements as a relation of the respective hydraulic and mechanical powers increasing in the power stream from the shaft or piston rod of a hydraulic motor to the pump shaft is a form of precise description of the value of those efficiencies

* description of the power of losses and energy efficiencies (presented in references [7-10]) is based on the principle of equality of the power absorbed by the pump with the sum of hydraulic motor useful power and power of losses in the system elements, and also on the principle of equality of the system energy efficiency, expressed as a relation of the motor useful power to the pump absorbed power, with the product of the system element energy efficiencies

comparing the power of losses in the system elements gives an information facilitating the system design

wesenting the fields of the power of losses in the system elements allows to draw conclusions about e.g. minimization of the power of structural volumetric and pressure losses in the motor speed throttling control assembly elements, in the proportional control systems and in the hydraulic servomechanism systems

graphical interpretation, by means of the field areas of the power of the energy losses in the hydrostatic drive system elements and of power developed by the elements, allows to compare powers of those losses with the area of the field of reference power given by the product $\mathrm{Q}_{\mathrm{Pt}} \mathrm{p}_{\mathrm{n}}$ of theoretical pump capacity and the system nominal pressure

* graphical interpretation of the power of losses allows to evaluate directly the energy savings after introducing the energy - saving solutions, allows to compare directly the energy losses due to change of the working medium viscosity or replacing the oil by oil - water emulsion or water.

References $[8,10]$ present an example (without any comment) of the graphical interpretation of the power of losses in a system with the hydraulic motor speed series throttling control fed by a constant capacity pump cooperating with an overflow valve in a constant pressure system.

This publication presents and analyses the field areas of the power of energy losses in the hydraulic system elements with different rotational hydraulic motor speed control structures. Deliberations allow to realise the rules deciding of the size of fields of power losses in the instantaneous motor operation parameters required by the motor driven device, i.e. instantaneous load $\mathrm{M}_{\mathrm{M}}$ and speed $\omega_{\mathrm{M}}\left(\mathrm{n}_{\mathrm{M}}\right)$. Deliberations allow to draw conclusions on achieving high energy efficiency $\eta$ of a system with selected structure and also conditions that must be fulfilled in order to achieve that high efficiency. Deliberations allow also to compare the power of losses connected with the used hydraulic motor speed control structure and the power $\mathrm{P}_{\mathrm{Pc}}$ absorbed (consumed) by the pump from the drive (electric or internal combustion) motor, the power necessary to ensure the required useful power $\mathrm{P}_{\mathrm{Mu}}=\mathrm{M}_{\mathrm{M}} \omega_{\mathrm{M}}$ of the pump driven hydraulic motor.

The paper consists of two parts. This Part I presents graphical interpretation of the power of energy losses and power developed in the elements of systems of the rotational hydraulic motor speed series throttling control, Part II - the same problems but related to the systems with parallel throttling control and volumetric control of the rotational hydraulic motor speed.

\section{SYSTEM OF THE MOTOR SPEED SERIES THROTTLING CONTROL FED BY A CONSTANT CAPACITY PUMP COOPERATING WITH AN OVERFLOW VALVE IN CONSTANT PRESSURE CONDITIONS}

Fig. 2 presents graphical interpretation of the power of energy losses in elements of an individual system with the rotational hydraulic motor speed series throttling control, fed by a constant capacity pump cooperating with an overflow valve in a constant pressure system $p=c t e \approx p_{n}$. 


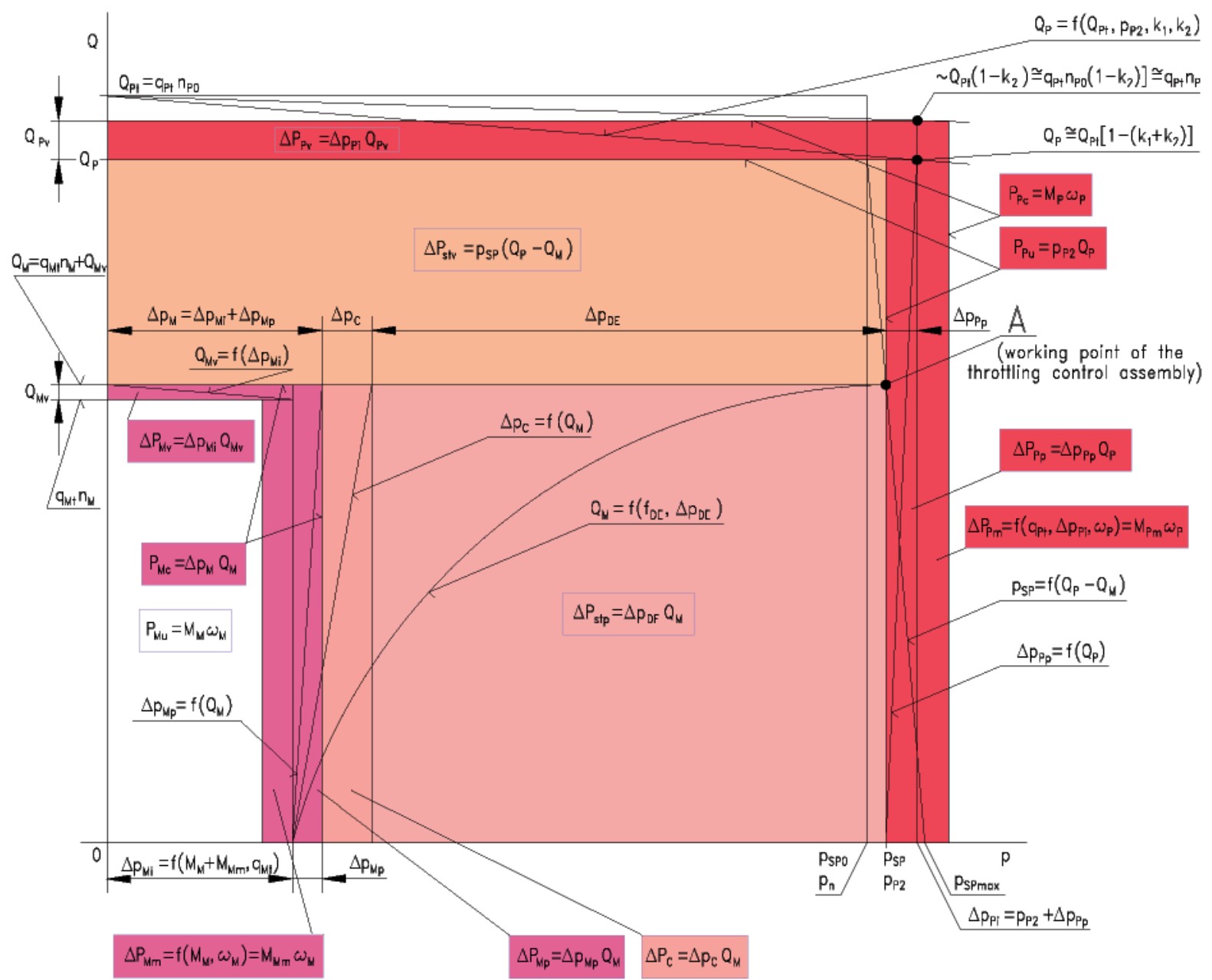

Fig. 2. Graphical interpretation of power losses in a hydrostatic drive and control system elements. Individual system with rotational hydraulic motor speed series throttling control fed by a constant capacity pump cooperating with an overflow valve in a constant pressure system: $p=c t e \approx p_{n}$ (coefficient , a " of pressure increase in the overflow valve a $>0$ ); the series throttling control assembly in the form of: 1. servo-valve, 2. proportional directional valve, 3. set throttling valve, 4. set two - way flow regulator; $\boldsymbol{k}_{1}$ - coefficient of the intensity $Q_{P v}$ of volumetric losses in the pump; $\boldsymbol{k}_{2}$ - coefficient of the decrease of pump shaft rotational speed $n_{P}$ compared with speed $n_{P 0}$ of unloaded pump

The series throttling control assembly used in the system may be a servo-valve or proportional directional valve (Fig. 3 ) or else a set throttling valve or a set two - way flow regulator placed at the motor inlet (Fig. 4).

Graphical interpretation (Fig. 2) of the power of energy loss (in the system elements) field area and field area of power developed in those elements allows to compare the losses with the field area of reference power determined by the product $\mathbf{p}_{\mathbf{n}} \mathbf{Q}_{\mathrm{Pt}}$ of the system nominal pressure $\mathbf{p}_{\mathbf{n}}$ (assumed here as opening pressure $\mathrm{p}_{\mathrm{SP} 0}$ of the overflow valve) and the theoretical capacity $Q_{\mathrm{Pt}}=q_{\mathrm{Pt}} \mathbf{n}_{\mathrm{P} 0}$ of the pump.

Nominal pressure $\mathrm{p}_{\mathrm{n}}$ of the pump operation corresponds to the need of assuring maximum decrease $\Delta \mathrm{p}_{\mathrm{Mmax}}$ of the hydraulic motor pressure guaranteeing (with a given capacity $\mathrm{q}_{\mathrm{Mt}}$ per one motor revolution) meeting the maximum torque $\mathrm{M}_{\mathrm{Mmax}}$ that the motor may be loaded with, from time to time, by the driven device.

The theoretical pump capacity $\mathrm{Q}_{\mathrm{pt}}$, on the other hand, meets the need of assuring maximum hydraulic shaft angular speed $\omega_{M \max }$ (rotational speed $\mathrm{n}_{\mathrm{M} \max }$ ) required by the driven device.

It has to be noted that assumption of an equal field $p_{n} Q_{p_{t}}$ of reference power in all the control structures leads to slightly different ranges of the change of speed $0 \leq \omega_{\mathrm{M}} \leq \omega_{\mathrm{Mmax}}$ and load $0 \leq \mathrm{M}_{\mathrm{M}} \leq \mathrm{M}_{\mathrm{Mmax}}$ of the hydraulic motor controlled by those structures.

The actual hydraulic motor useful power $\mathrm{P}_{\mathrm{Mu}}=\mathrm{M}_{\mathrm{M}} \omega_{\mathrm{M}}$ is a result of the product of current torque $\mathrm{M}_{\mathrm{M}}$, which the hydraulic motor is loaded with by the driven device, and the current motor shaft angular speed $\omega_{\mathrm{M}}$, also required at a given moment by the driven device.

Therefore, the motor useful power $\mathrm{P}_{\mathrm{Mu}}$ depends on the current requirements of the driven device and is independent of the control structure and of the losses in elements of the hydrostatic drive system with a defined structure.

But powers $\Delta \mathrm{P}$ of losses in the hydraulic system elements are a function of the current value of useful power $\mathrm{P}_{\mathrm{Mu}}$, i.e. a function of current torque $\mathrm{M}_{\mathrm{M}}$ and current motor shaft speed $\omega_{\mathrm{M}}$. Besides, it depends on the structure of the motor speed control system and on the quality of the hydraulic system components (the level of energy losses in them).

In Fig. 2, the actual hydraulic motor useful power $\mathrm{P}_{\mathrm{Mu}}=$ $=\mathrm{M}_{\mathrm{M}} \omega_{\mathrm{M}}$, transmitted to the driven device by the motor shaft, is presented as the field of the white rectangular, with the following fields ,,added" to it:

$\lambda$ field $\Delta \mathrm{P}_{\mathrm{Mm}}=\mathrm{M}_{\mathrm{Mm}} \omega_{\mathrm{M}}$ of the power of mechanical losses in the hydraulic motor

A field $\Delta \mathrm{P}_{\mathrm{Mv}}=\Delta \mathrm{p}_{\mathrm{Mi}} \mathrm{Q}_{\mathrm{Mv}}$ of the power of volumetric losses in the hydraulic motor

$\lambda$ field $\Delta \mathrm{P}_{\mathrm{Mp}}=\Delta \mathrm{p}_{\mathrm{Mp}} \mathrm{Q}_{\mathrm{M}}$ of the power of pressure losses in the hydraulic motor

1 field $\Delta \mathrm{P}_{\mathrm{C}}=\Delta \mathrm{p}_{\mathrm{C}} \mathrm{Q}_{\mathrm{M}}$ of the power of pressure losses in the system conduits

入 field $\Delta \mathrm{P}_{\text {sth }}=\Delta \mathrm{p}_{\mathrm{DE}} \mathrm{Q}_{\mathrm{M}}$ of the power of structural pressure losses in the throttling control assembly (in servo-valve, directional proportional valve, set throttling valve or set two - way flow regulator) 


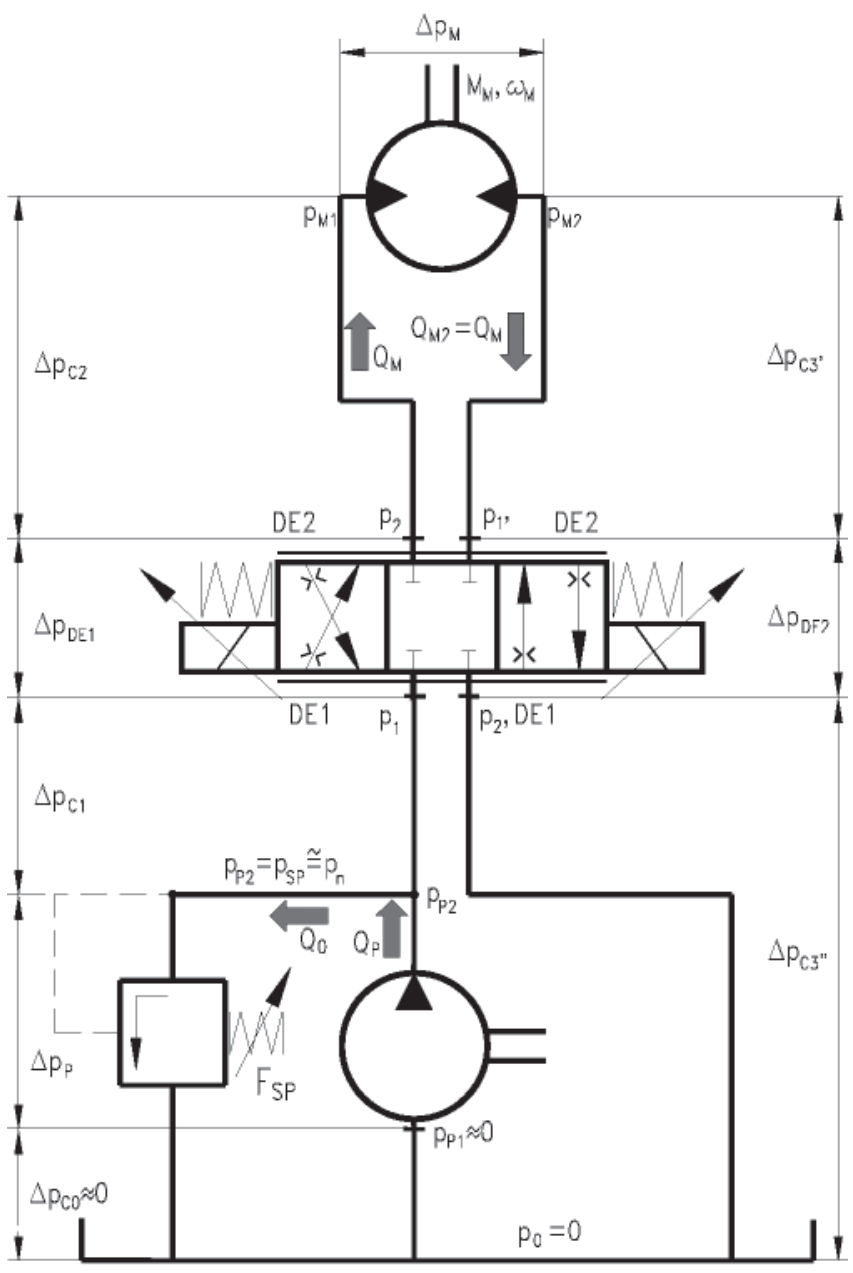

Fig. 3. Individual system of the rotational hydraulic motor speed series throttling control fed by a constant capacity pump cooperating with an overflow valve in constant pressure conditions $p_{P 2}=$ cte $\approx p_{n}$; the throttling control assembly in the form of servo - valve or proportional directional valve

$\lambda$ field $\Delta \mathrm{P}_{\text {stv }}=\mathrm{p}_{\mathrm{SP}}\left(\mathrm{Q}_{\mathrm{P}}-\mathrm{Q}_{\mathrm{M}}\right)$ of the power of structural volumetric losses in the throttling control assembly (in overflow valve)

$\lambda$ field $\Delta \mathrm{P}_{\mathrm{Pp}}=\Delta \mathrm{p}_{\mathrm{Pp}} \mathrm{Q}_{\mathrm{P}}$ of the power of pressure losses in the pump

1 field $\Delta \mathrm{P}_{\mathrm{Pv}}=\Delta \mathrm{p}_{\mathrm{Pi}} \mathrm{Q}_{\mathrm{Pv}}$ of the power of volumetric losses in the pump

$\lambda$ field $\Delta \mathrm{P}_{\mathrm{Pm}}=\mathrm{M}_{\mathrm{Pm}} \omega_{\mathrm{P}}$ of the power of mechanical losses in the pump.

The sum of the field areas of the hydraulic motor current useful power $\mathrm{P}_{\mathrm{Mu}}$ rectangle and the field areas of rectangles $\Delta \mathrm{P}$ representing the power of individual losses occurring at a given moment of work in the hydrostatic drive and control system elements constitutes the rectangle field area corresponding to the actual power $\mathrm{P}_{\mathrm{P}_{\mathrm{c}}}$ absorbed (consumed) by the pump from the electric or internal combustion driving motor, resulting from the product of current torque $\mathrm{M}_{\mathrm{p}}$ and current pump shaft angular speed $\omega_{\mathrm{P}}\left(\mathrm{P}_{\mathrm{Pc}_{\mathrm{c}}}=\mathrm{M}_{\mathrm{p}} \omega_{\mathrm{p}}\right)$.

Power $\mathrm{P}_{\mathrm{Pc}_{\mathrm{c}}}$ absorbed by the pump from its drive motor is greater than the reference power $\mathrm{p}_{\mathrm{n}} \mathrm{Q}_{\mathrm{pt}}$ resulting from the product of nominal pressure $\mathrm{p}_{\mathrm{n}}$ and theoretical pump capacity $\mathrm{Q}_{\mathrm{Pt}}$.

The required level of nominal pressure $p_{n}$ of pump operation and the required level of pump theoretical capacity $\mathrm{Q}_{\mathrm{pt}}$ during the system operation, as well as the current small loading torque $\mathrm{M}_{\mathrm{M}}$ and current small hydraulic motor shaft angular speed $\omega_{\mathrm{M}}$ are decisive in that motor speed throttling control structure of a) $P_{p_{c}}, M_{p}, \omega_{p}$

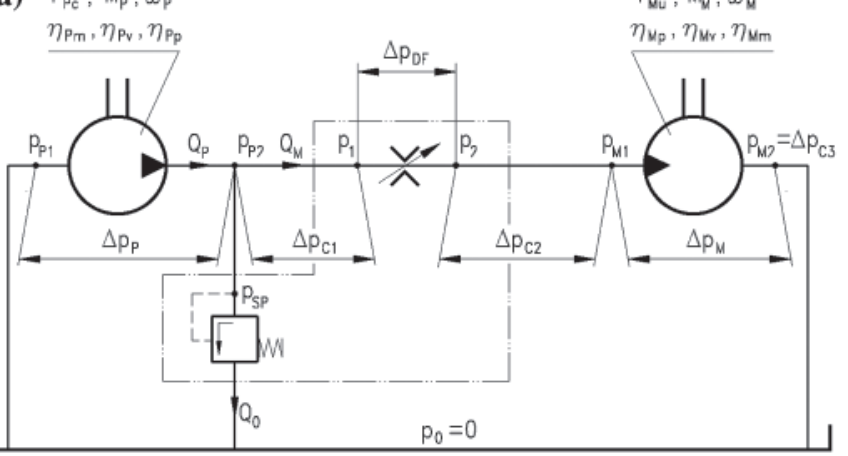

b) $P_{p_{c}}, M_{p}, \omega_{p}$

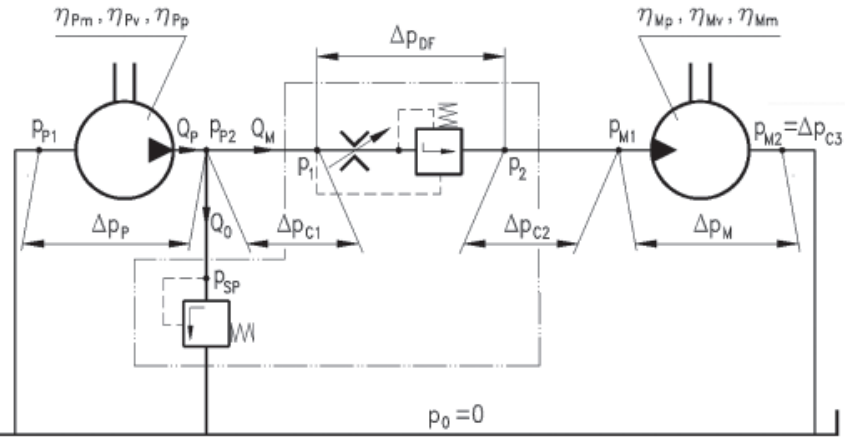

Fig. 4. Individual system of the rotational hydraulic motor speed series throttling control fed by a constant capacity pump cooperating with an overflow valve in constant pressure conditions $p_{P 2}=c t e \approx p_{n}$; the throttling control assembly in the form of: a) set throttling valve, b) set two - way flow regulator

temporary power $\Delta \mathrm{P}_{\text {stp }}$ of structural pressure losses and power $\Delta \mathrm{P}_{\text {stv }}$ of structural volumetric losses. This is then accompanied by a very low value of the overall energy efficiency $\eta$ of the system.

The power $\Delta \mathrm{P}_{\text {stp }}$ of the structural pressure losses in the throttling control assembly may be reduced almost to zero during the hydraulic motor operation at the maximum shaft load $\mathrm{M}_{\mathrm{Mmax}}$.

The power $\Delta \mathrm{P}_{\text {stv }}$ of the structural volumetric losses in the throttling control assembly may be reduced almost to zero in a situation when the hydraulic motor operates with maximum angular speed $\omega_{\text {Mmax }}$ (rotational speed $n_{M \max }$ ).

The hydraulic motor operation with maximum load $\mathrm{M}_{\mathrm{Mmax}}$ and simultaneous maximum speed $\omega_{M \max }\left(\mathrm{n}_{\mathrm{Mmax}}\right)$ may cause minimization of the power of losses connected with the motor speed throttling control and the sum of energy losses in the system consists of the hydraulic motor losses, the conduit losses and pump losses. The overall system efficiency $\eta$ reaches then a high value $\eta_{\max }$, close to the value of energy efficiency $\eta_{\max }$ of a system with the motor speed volumetric control (by a variable capacity pump).

However, in order to be able, in a system with series throttling control, to load the hydraulic motor with a maximum torque $\mathrm{M}_{\mathrm{Mmax}}$ close to the maximum load $\mathrm{M}_{\mathrm{Mmax}}$ of the motor in a system with volumetric speed control, the throttling slot of the throttling proportional control valve (or of the throttling valve) has to be increased to the size requiring a small decrease $\Delta \mathrm{p}_{\mathrm{DEmin}} \approx$ $\approx 0$ of pressure at the maximum flow intensity $\mathrm{Q}_{\mathrm{M} \max } \approx \mathrm{Q}_{\mathrm{p}}$.

On the other hand, in order to be able, in a system with series throttling control, to set, with a throttling proportional control valve or a throttling valve, the maximum intensity $\mathrm{Q}_{\mathrm{Mmax}} \approx \mathrm{Q}_{\mathrm{p}}$ i.e. close to the pump capacity, an overflow valve has to be used in the system to stabilize the pressure level $\mathrm{p}_{\mathrm{SP}} \approx$ $\approx \mathrm{p}_{\mathrm{n}}$ of the pump operation at the flow intensity $\mathrm{Q}_{\mathrm{P}}-\mathrm{Q}_{\mathrm{M}} \approx 0$ (i.e. close to zero). 
System of the motor speed series throttling control fed by a constant capacity pump cooperating with an overflow valve controlled in variable pressure conditions

Fig. 5 presents graphical interpretation of the power of energy losses in the elements of an individual system with the rotational hydraulic motor speed series throttling control, fed by a constant capacity pump cooperating with an overflow valve controlled in a variable pressure system: $\mathbf{p}=$ var. The series throttling control assembly used in the system may have a form of servo-valve or proportional directional control valve (Fig. 6) or else a set throttling valve (creating, with the controlled overflow valve, a set three - way flow regulator) or a set two - way flow regulator placed at the motor inlet (Fig. 7).

The pump operation pressure $\mathrm{p}_{\mathrm{P} 2}$, controlled by the overflow valve with remote pilot control (SPS), is set to a level higher by a value $\Delta \mathrm{p}_{\mathrm{SPS}}=\Delta \mathrm{p}_{\mathrm{DE} 1 \mid \mathrm{f}_{\mathrm{DE} \text { max }}, \mathrm{Q}_{\mathrm{Pt}}}+\Delta \mathrm{p}_{\mathrm{Clmax}}=$ cte than the current pressure $\mathrm{p}_{2}$ in the throttling proportional valve outlet conduit to the hydraulic motor. The pressure difference $\Delta \mathrm{p}_{\mathrm{SPS}}=\mathrm{p}_{\mathrm{P} 2}-\mathrm{p}_{2}$ must allow to achieve, through the throttling proportional valve slot DE1, controlling the hydraulic motor feed flow intensity $Q_{M}$, the flow intensity $Q_{M}$ equal to the theoretical pump capacity $\mathrm{Q}_{\mathrm{Pt}}\left(\mathrm{Q}_{\mathrm{M}}=\mathrm{Q}_{\mathrm{Pt}}\right)$. The area of DE1 slot reaches then the maximum value $f_{D E \max }$, with a possibility of achieving the pressure decrease $\Delta \mathrm{p}_{\mathrm{DE} 1 \mid \mathrm{f}_{\mathrm{DEl} \text { max }}, \mathrm{Q}_{\mathrm{Pt}}}$ required by the throttling proportional valve structure, with simultaneous ability to overcome the maximum flow resistance value $\Delta \mathrm{p}_{\mathrm{Clmax}}$ in the segment between the pump and the throttling proportional valve. Pressure $\mathrm{p}_{1}$ before the throttling proportional valve slot DE1 equals $\mathrm{p}_{1}=\mathrm{p}_{\mathrm{P} 2}-\Delta \mathrm{p}_{\mathrm{C} 1}$.

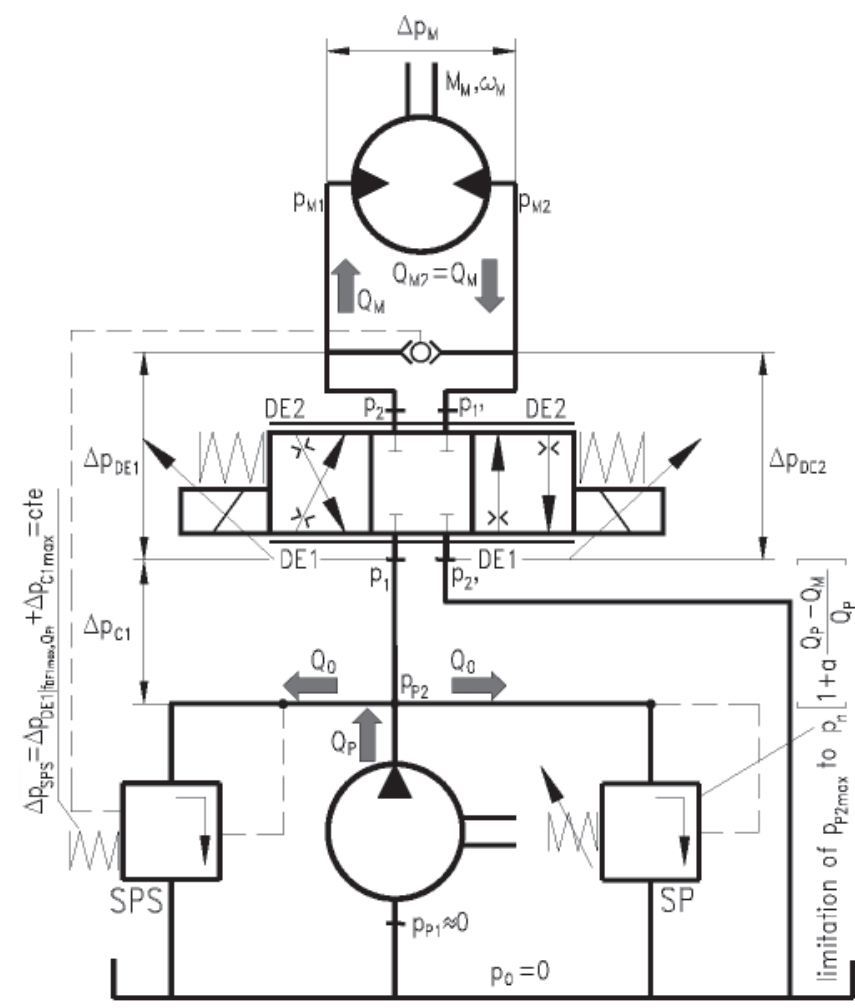

Fig. 6. Individual system of the rotational hydraulic motor speed series throttling control fed by a constant capacity pump cooperating with an overflow valve controlled in variable pressure conditions $p_{P 2}=$ var; the throttling control assembly in a form of servo - valve or directional proportional valve

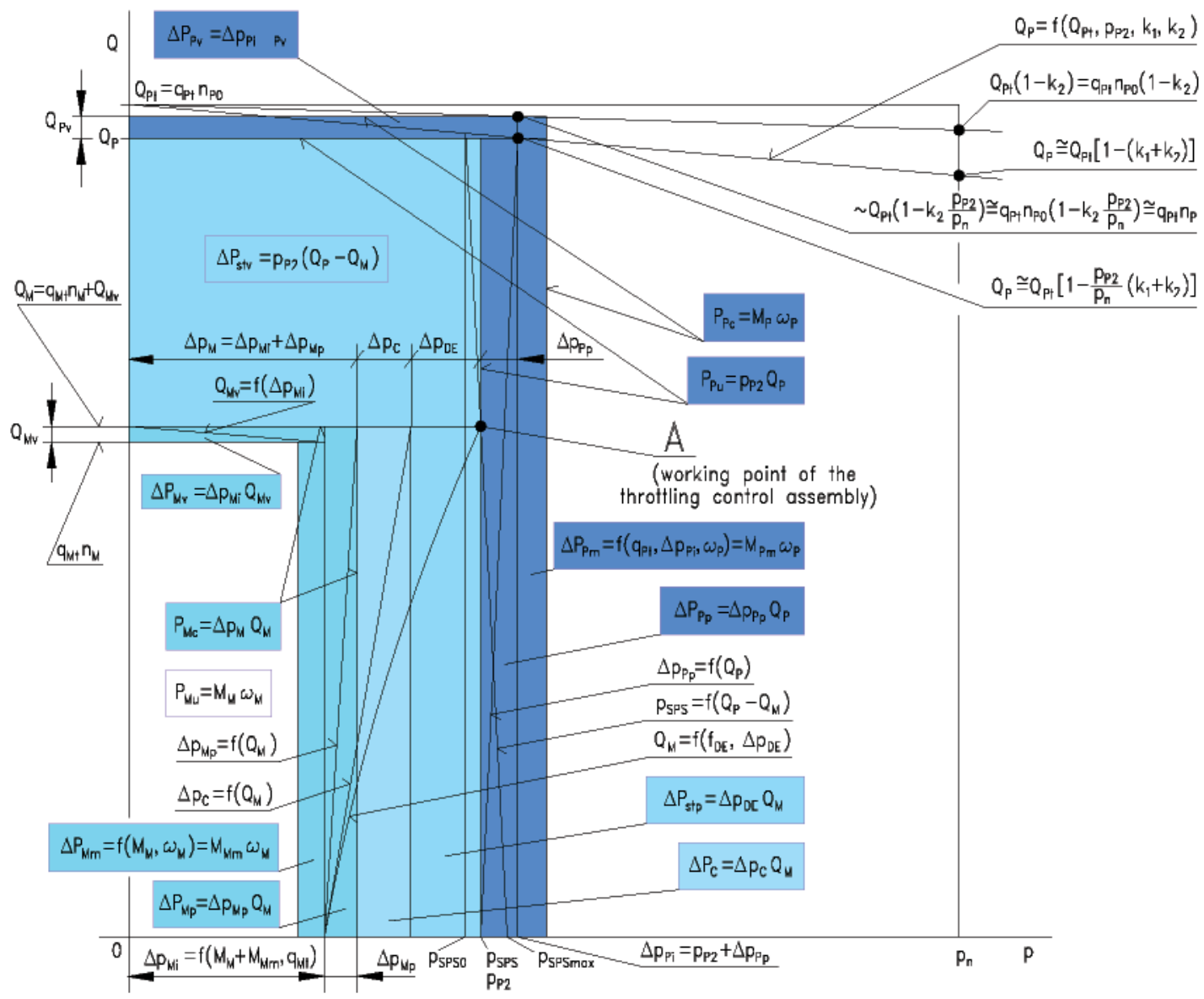

Fig. 5. Graphical interpretation of power losses in a hydrostatic drive and control system elements. Individual system with rotational hydraulic motor speed series throttling control fed by a constant capacity pump cooperating with a controlled overflow valve in a variable pressure system $-p=$ var (coefficient , $a$ " of pressure increase in the controlled overflow valve $a>0$ ); the series throttling control assembly in the form of: 1 . servo-valve, 2. proportional directional valve; 3. set throttling valve (together with controlled overflow valve forming a three - way set flow regulator) 
The current value of pump discharge pressure $\mathrm{p}_{\mathrm{p} \text {, }}$, higher by $\Delta \mathrm{p}_{\mathrm{SPS}}$ than the current value of the throttling proportional valve outlet (to the hydraulic motor) pressure $\mathrm{p}_{2}$, is a result of the pressure $\mathrm{p}_{\mathrm{M} 1}$ required by the motor at its inlet. The maximum limit value $\mathrm{p}_{\mathrm{p} 2 \mathrm{max}}$ of pressure in the pump discharge conduit is determined by the overflow valve SP with opening pressure $\mathrm{p}_{\mathrm{SP} 0}$ equal to the system nominal pressure $\mathrm{p}_{\mathrm{n}}$.

This solution significantly reduces (compared with the constant pressure feeding system) the power $\Delta \mathrm{P}_{\text {stp }}=\Delta \mathrm{p}_{\mathrm{DE}} \mathrm{Q}_{\mathrm{M}}$ of structural pressure losses in the throttling control assembly, occurring during the hydraulic motor loading with a decreasing torque $\mathrm{M}_{\mathrm{M}}$

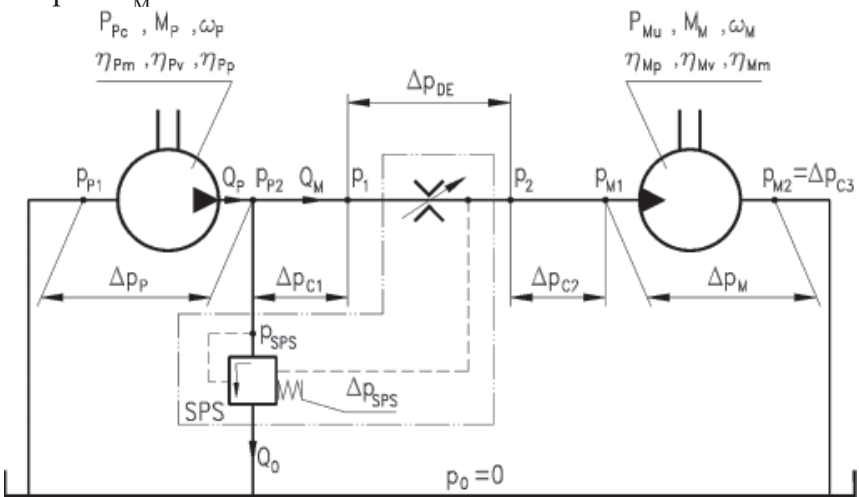

Fig. 7. Individual system of the rotational hydraulic motor speed series throttling control fed by a constant capacity pump cooperating with an overflow valve controlled in variable pressure conditions $p_{P 2}=$ var; the

throttling control assembly in a form of three - way flow regulator

The power $\Delta \mathrm{P}_{\text {stv }}=\mathrm{p}_{\mathrm{SPS}}\left(\mathrm{Q}_{\mathrm{P}}-\mathrm{Q}_{\mathrm{M}}\right)$ of structural volumetric losses in the controlled overflow valve is then also reduced, although the flow intensity $\mathrm{Q}_{0}=\mathrm{Q}_{\mathrm{P}}-\mathrm{Q}_{\mathrm{M}}$ of volumetric losses in that valve increases slightly compared with the constant pressure feeding system (Fig. 2) due to a higher pump capacity $\mathrm{Q}_{\mathrm{P}}$ (at a lower pump operating pressure $\mathrm{p}_{\mathrm{P} 2}$ ).

In a rotational hydraulic motor operating in both systems ( $p=$ cte and $p=$ var) the three values of power of energy losses $\left(\Delta \mathrm{P}_{\mathrm{Mm}}, \Delta \mathrm{P}_{\mathrm{Mv}}\right.$ and $\left.\Delta \mathrm{P}_{\mathrm{Mp}}\right)$ are practically the same (with a slight tendency to lower the power $\Delta \mathrm{P}_{\mathrm{Mm}}$ of mechanical losses and power $\Delta \mathrm{P}_{\mathrm{Mv}}$ of volumetric losses in a motor operating in a $\mathrm{p}=$ $=$ var system).

Power $\Delta \mathrm{P}_{\mathrm{C}}=\Delta \mathrm{p}_{\mathrm{C}} \mathrm{Q}_{\mathrm{M}}$ of pressure losses in the $\mathrm{p}=$ var system conduits is the same as in a $\mathrm{p}=$ cte system.

In a pump, due to its operation in a variable pressure feeding system, the power $\Delta \mathrm{P}_{\mathrm{Pp}}=\Delta \mathrm{p}_{\mathrm{Pp}} \mathrm{Q}_{\mathrm{P}}$ of pressure losses is slightly increased, power $\Delta \mathrm{P}_{\mathrm{P}_{\mathrm{V}}}=\Delta \mathrm{p}_{\mathrm{P}_{\mathrm{P}}} \mathrm{Q}_{\mathrm{P}_{\mathrm{P}}}$ of volumetric losses is decreased and power $\Delta \mathrm{P}_{\mathrm{Pm}}=\mathrm{M}_{\mathrm{Pm}} \omega_{\mathrm{P}}$ of mechanical losses is also decreased.

In effect, when the hydraulic motor is loaded with a small torque $\mathrm{M}_{\mathrm{M}}$, the power $\Delta \mathrm{P}_{\mathrm{Pc}}=\mathrm{M}_{\mathrm{P}} \omega_{\mathrm{P}}$ absorbed by the pump from the drive (electric or internal combustion) motor is also significantly reduced, which, with an unchanged hydraulic motor useful power $\mathrm{P}_{\mathrm{Mm}}=\mathrm{M}_{\mathrm{M}} \omega_{\mathrm{M}}$, increases the overall system energy efficiency $\eta$ compared with the constant pressure feeding system efficiency $\eta$.

Both structures $(p=$ cte and $p=$ var $)$ of the hydraulic motor speed series throttling control, fed by a constant capacity pump, may achieve, during maximum motor load $\mathrm{M}_{\mathrm{M} \max }$ and simultaneous maximum speed $\omega_{\mathrm{M} \max }\left(\mathrm{n}_{\mathrm{M} \max }\right)$, the same maximum overall system efficiency $\eta_{\max }$. It is close to the maximum energy efficiency $\eta_{\text {max }}$ of a system with volumetric control (by a variable capacity pump) of hydraulic motor speed. The $p=$ var system becomes then a $p=$ cte system, therefore the operating conditions of both systems are the same and structural losses $\Delta \mathrm{P}_{\text {stp }}$ and $\Delta \mathrm{P}_{\text {stv }}$ in the throttling control assembly may be practically eliminated. However, similarly as in the constant capacity pump system $p=$ cte, it requires increased area of the $\mathrm{f}_{\text {DEmax }}$ slot in the throttling directional control valve (throttling valve) to a size requiring slight pressure decrease $\Delta \mathrm{p}_{\mathrm{DEmin}} \approx 0$ at the maximum flow intensity $\mathrm{Q}_{\mathrm{Mmax}}=\mathrm{Q}_{\mathrm{p}^{\text {. }}}$. It requires also the use of a controlled overflow valve stabilizing the value $\Delta \mathrm{p}_{\mathrm{SPS}}=$ $=\mathrm{p}_{\mathrm{P} 2}-\mathrm{p}_{2}=$ cte also at the flow intensity $\mathrm{Q}_{\mathrm{P}}-\mathrm{Q}_{\mathrm{M}} \approx 0$ (close to zero) and an overflow valve stabilizing the pressure level $\mathrm{p}_{\mathrm{SP}} \approx$ $\approx \mathrm{p}_{\mathrm{n}}$ at the flow intensity $\mathrm{Q}_{\mathrm{P}}-\mathrm{Q}_{\mathrm{M}} \approx 0$.

\section{SYSTEM OF THE MOTOR SPEED SERIES THROTTLING CONTROL FED BY A VARIABLE CAPACITY PUMP COOPERATING WITH REGULATOR IN THE CONSTANT PRESSURE CONDITIONS}

Fig. 8 describes the power of energy losses in the elements of an individual system with the rotational hydraulic motor speed series throttling control, fed by a variable capacity pump cooperating with a pressure regulator in a constant pressure system $\mathbf{p}=\mathbf{c t e} \approx \mathbf{p}_{\mathrm{n}}$. The series throttling control assembly used in the system may have a form of servo-valve or proportional directional control valve (Fig. 9) or else a set throttling or a set two-way flow regulator placed in the motor inlet (Fig. 10 - example of a central system with parallely situated motors and with variable capacity pump cooperating with pressure regulator $\mathrm{p}_{\mathrm{P} 2}=$ cte $\approx \mathrm{p}_{\mathrm{n}}-$ during one motor operation).

The use, as a source of supply of the hydraulic motor series throttling control system, an assembly consisting of a variable capacity pump and a constant pressure $\mathrm{p}_{\mathrm{P} 2}=$ cte $\approx \mathrm{p}_{\mathrm{n}}$ regulator entirely eliminates structural volumetric losses. The current pump capacity $Q_{p}$ is adjusted by the pressure regulator to the current flow intensity $Q_{M}$ set by the throttling assembly, therefore the pump capacity $\mathrm{Q}_{\mathrm{p}}$ is equal to the hydraulic motor absorption capacity $\mathrm{Q}_{\mathrm{M}}\left(\mathrm{Q}_{\mathrm{P}}=\mathrm{Q}_{\mathrm{M}}\right)$ and the power $\Delta \mathrm{P}_{\text {stv }}$ of structural volumetric losses is then equal to zero $\left(\Delta \mathrm{P}_{\mathrm{stv}} \stackrel{\mathrm{stv}}{=}\right.$ $\left.=\mathrm{p}_{\mathrm{P} 2}\left(\mathrm{Q}_{\mathrm{P}}-\mathrm{Q}_{\mathrm{M}}\right)=0\right)$.

Power $\Delta \mathrm{P}_{\mathrm{stp}}=\Delta \mathrm{p}_{\mathrm{DE}} \mathrm{Q}_{\mathrm{M}}$ of structural pressure losses in the series throttling control assembly fed at a constant pressure by a variable capacity pump fitted with a pressure regulator is close to the power of structural pressure losses when the assembly is fed by pressure $\mathrm{p}_{\mathrm{P} 2}=$ cte $\approx \mathrm{p}_{\mathrm{n}}$ of a constant capacity pump cooperating with an overflow valve (Fig. 2).

Power of mechanical losses $\Delta \mathrm{P}_{\mathrm{Mm}}$, volumetric losses $\Delta \mathrm{P}_{\mathrm{Mv}}$ and pressure losses $\Delta \mathrm{P}_{\mathrm{Mp}}$ occurring in the rotational hydraulic motor remains practically unchanged.

Power $\Delta \mathrm{P}_{\mathrm{C}}=\Delta \mathrm{p}_{\mathrm{C}} \mathrm{Q}_{\mathrm{M}}$ of pressure losses in the system conduits is not changed here compared with the above described systems with a constant capacity pump.

In the variable capacity pump feeding (together with the pressure regulator) the throttling control assembly at the pressure $\mathrm{p}_{\mathrm{P} 2}=$ cte $\approx \mathrm{p}_{\mathrm{n}}$, the power of pressure losses $\Delta \mathrm{P}_{\mathrm{Pp}}=\Delta \mathrm{p}_{\mathrm{Pp}} \mathrm{Q}_{\mathrm{P}}$ is reduced (due to decrease of $\mathrm{Q}_{\mathrm{P}}$ and $\Delta \mathrm{p}_{\mathrm{Pp}}$ ). Power $\Delta \mathrm{P}_{\mathrm{Pv}}=\Delta \mathrm{p}_{\mathrm{Pi}} \mathrm{Q}_{\mathrm{Pv}}$ of volumetric losses in the pump is practically the same as in a constant capacity pump operating at pressure $\mathrm{p}_{\mathrm{P} 2}=$ cte $\approx \mathrm{p}_{\mathrm{n}}$. However, the power $\Delta \mathrm{P}_{\mathrm{Pm}}=\mathrm{M}_{\mathrm{Pm}} \omega_{\mathrm{p}}$ of mechanical losses in the pump is reduced compared with a constant capacity pump operating in the $\mathrm{p}_{\mathrm{P} 2}=$ cte $\approx \mathrm{p}_{\mathrm{n}}$ system (due to decrease of $\mathrm{M}_{\mathrm{Pm}}$ ).

The use, as a hydraulic motor series throttling speed control system feeding source, a variable capacity pump with pressure regulator, operating at pressure $\mathrm{p}_{\mathrm{p} 2}=$ cte $\approx \mathrm{p}_{\mathrm{n}}$, allows, during the motor run with small speed $\omega_{M}\left(n_{M}\right)$, to reduce significantly the power $\mathrm{P}_{\mathrm{P}_{\mathrm{c}}}=\mathrm{M}_{\mathrm{P}} \omega_{\mathrm{P}}$ absorbed by the pump from the drive electric or internal combustion motor. With the unchanged useful power $\mathrm{P}_{\mathrm{Mu}}=\mathrm{M}_{\mathrm{M}} \omega_{\mathrm{M}}$ of the hydraulic motor, the entire system energy 


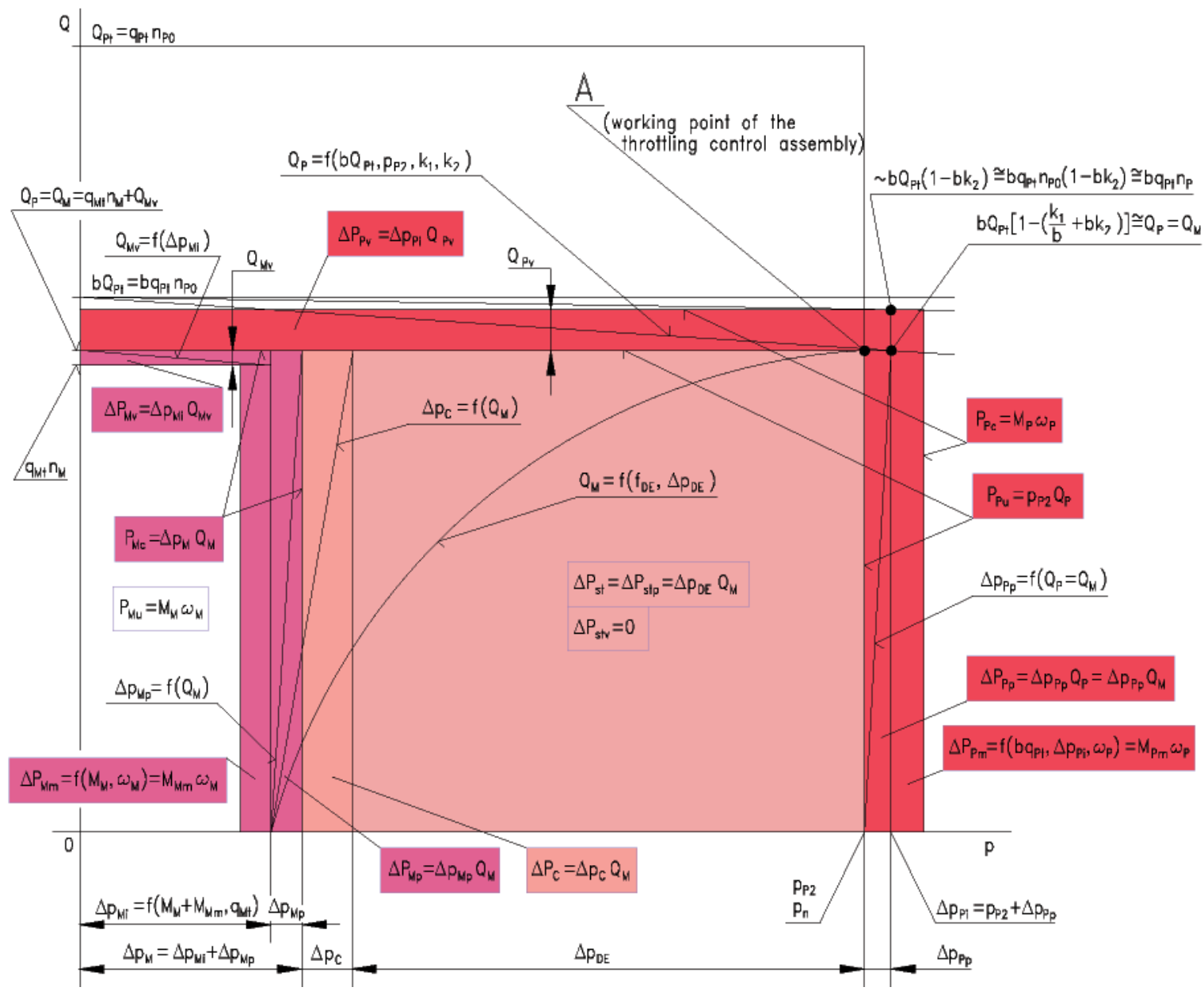

Fig. 8. Graphical interpretation of power losses in a hydrostatic drive and control system elements. Individual system with rotational hydraulic motor speed series throttling control fed by a constant capacity pump cooperating with pressure regulator in a constant pressure system: $p=$ cte $\approx p_{n}$ (coefficient , a ," of pressure increase in the regulator $\left.a_{1}=0\right)$; the series throttling control assembly in the form of: 1. servo-valve, 2. proportional directional valve,

$$
\text { 3. set throttling valve, 4. set two - way flow regulator }
$$

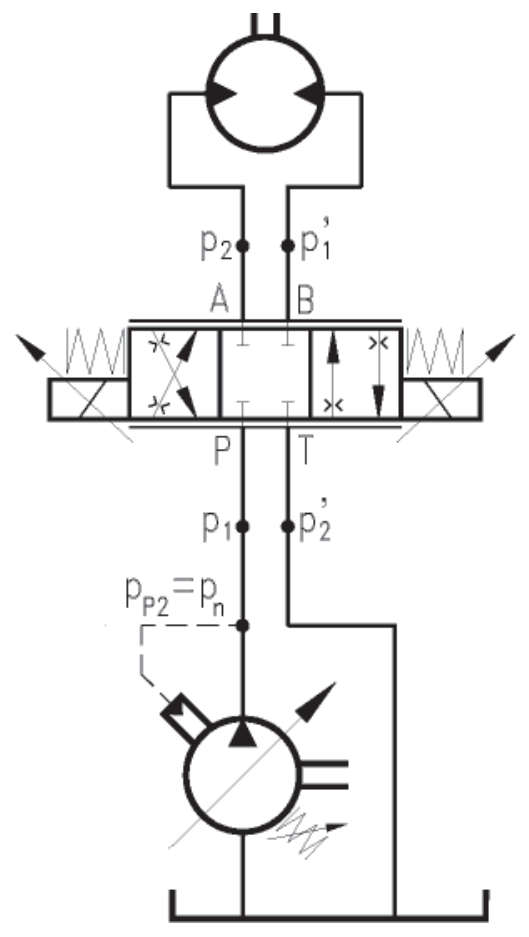

Fig. 9. Individual system with the rotational hydraulic motor speed series throttling control fed by a variable capacity pump cooperating with regulator in the constant pressure conditions $p_{P 2}=$ cte $\approx p_{n}$; the throttling control assembly in the form of servo-valve or proportional directional valve

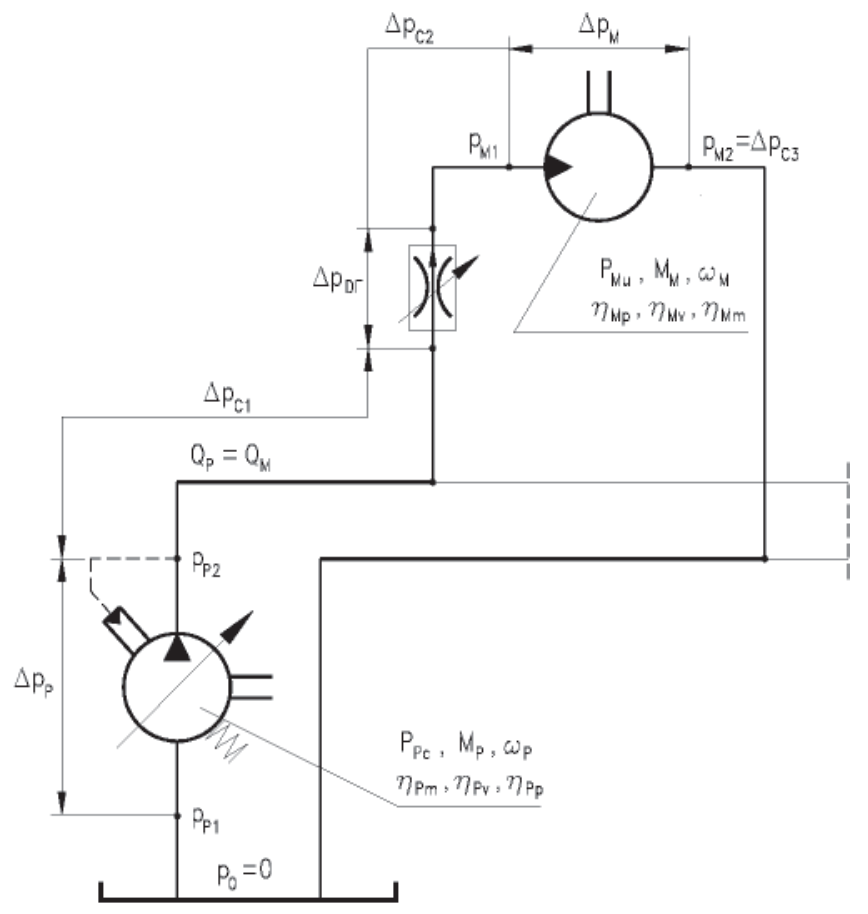

Fig. 10. Central system with parallelly situated motors and with variable capacity pump cooperating with pressure regulator in the constant pressure conditions $p_{P 2}=$ cte $\approx p_{n}-$ during one motor operation 
efficiency $\eta$ is significantly higher compared with efficiency $\eta$ of a constant pressure $(p=c t e)$ throttling assembly constant capacity pump feeding system.

The considered system may achieve, during the maximum hydraulic motor load $\mathrm{M}_{\mathrm{Mmax}}$ and in the whole range of the motor speed change $0 \leq \omega_{M} \leq \omega_{M \max }$, the overall efficiency $\eta$ close to the value of energy efficiency $\eta$ of a system with the motor speed volumetric control (by a variable capacity pump). The power $\Delta \mathrm{P}_{\mathrm{stp}}=\Delta \mathrm{p}_{\mathrm{DE}} \mathrm{Q}_{\mathrm{M}}$ of the structural pressure losses is then minimalized. It requires, in a system with the hydraulic motor speed series throttling control, an increased area of the $f_{\text {DEmax }}$ slot in the throttling directional control valve (or the throttling valve) to a size requiring slight pressure decrease $\Delta \mathrm{p}_{\mathrm{DEmin}} \approx 0$ at the maximum flow intensity $\mathrm{Q}_{\mathrm{M} \max }=\mathrm{Q}_{\mathrm{P} \max }$, i.e. equal to the full pump capacity. It requires also correct operation of the pump pressure regulator stabilizing the pump discharge pressure $\mathrm{p}_{\mathrm{P} 2}$ at the level $\mathrm{p}_{\mathrm{P} 2}=$ cte $\approx \mathrm{p}_{\mathrm{n}}$ in the whole range $0 \leq \mathrm{Q}_{\mathrm{P}} \leq \mathrm{Q}_{\mathrm{P} \max }$ of the pump capacity variation.

In a situation of simultaneous maximum load $\mathrm{M}_{\mathrm{Mmax}}$ and maximum speed $\omega_{\mathrm{Mmax}}$ of a hydraulic motor controlled by series throttling, the maximum achievable energy efficiency $\eta_{\max }$ of a system is close to the value $\eta_{\max }$ of a system with hydraulic motor speed volumetric control i.e. directly by a variable capacity pump.

The greatest energy savings in the considered series throttling control system, compared with a series control system fed by a constant pressure constant capacity pump, are obtained during the hydraulic motor operation at small speed $\omega_{M}\left(n_{M}\right)$.

\section{SYSTEM OF THE MOTOR SPEED SERIES THROTTLING CONTROL FED BY A VARIABLE CAPACITY PUMP COOPERATING WITH A LOAD SENSING REGULATOR IN THE VARIABLE PRESSURE CONDITIONS}

Fig. 11 illustrates the fields of power of energy losses in elements of an individual system with the rotational hydraulic motor speed series throttling control, fed by a variable capacity pump cooperating with the Load Sensing regulator in a variable pressure $\mathbf{p}=$ var system. The series throttling control assembly may have a form of servo-valve or proportional directional valve (Fig. 12) or else a set throttling valve or a set two - way flow regulator placed at the motor inlet (Fig. 13 - example of a central system with parallelly situated motors and with variable capacity pump cooperating with Load Sensing regulator - during one motor operation).

The use, as a supply source of the hydraulic motor speed series throttling control assembly, of a set consisting of a variable capacity pump cooperating with a Load Sensing (LS) regulator, totally eliminates the structural volumetric losses in a system. Similarly as in the series throttling control system fed by a variable capacity pump cooperating with the $\mathrm{p}_{\mathrm{p} 2}=\mathrm{cte} \approx \mathrm{p}_{\mathrm{n}}$ regulator, i.e. at the constant pressure feeding, the structural volumetric losses are eliminated here. Power $\Delta \mathrm{P}_{\text {stv }}$ of those losses is equal to zero $\left(\Delta \mathrm{P}_{\text {stv }}=\mathrm{p}_{\mathrm{P} 2}\left(\mathrm{Q}_{\mathrm{P}}-\mathrm{Q}_{\mathrm{M}}\right)=0\right)$,

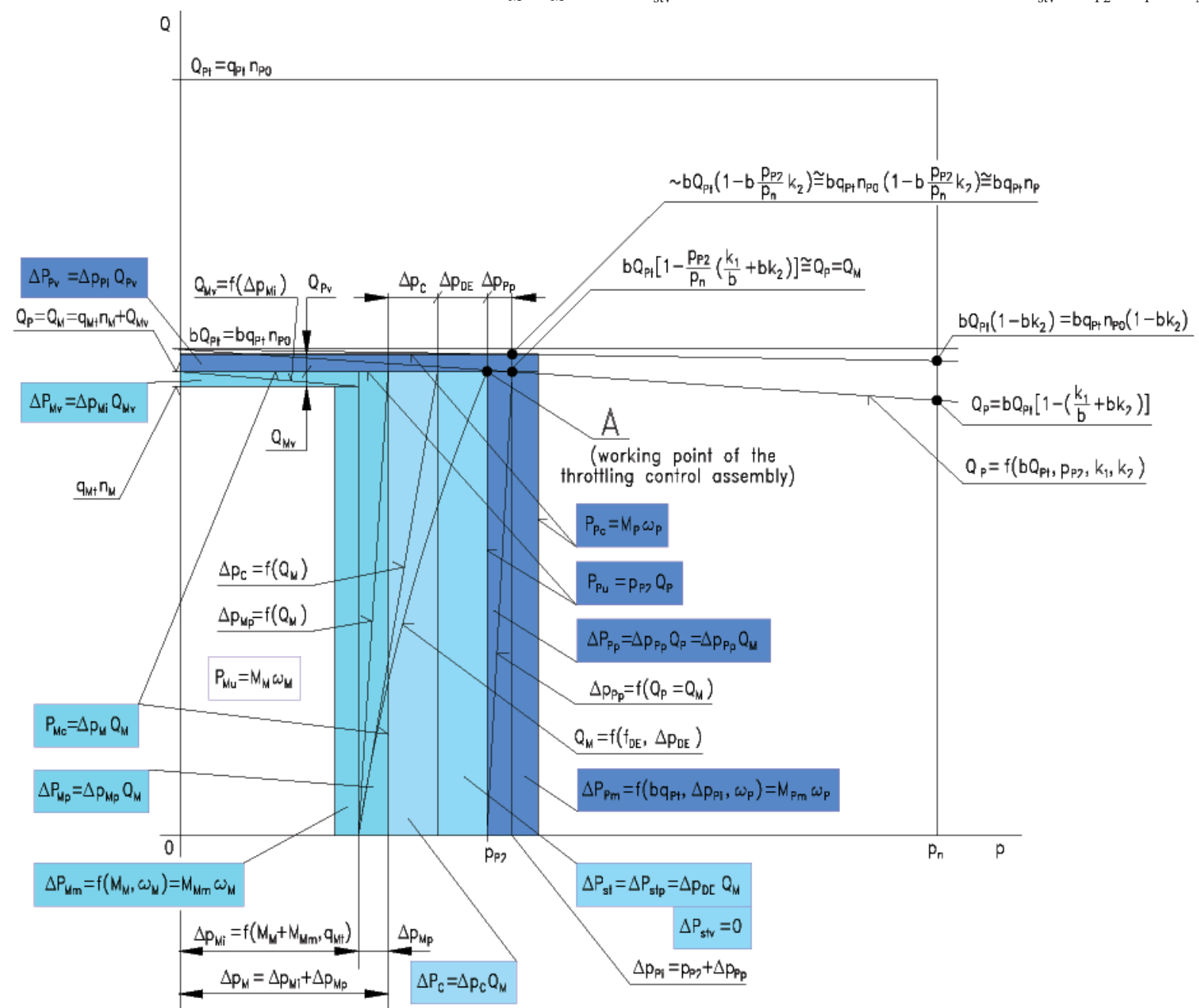

Fig. 11. Graphical interpretation of power losses in a hydrostatic drive and control system elements. Individual system with rotational hydraulic motor speed series throttling control fed by a variable capacity pump cooperating with the Load Sensing regulator in a variable pressure system: $p=$ var (coefficient , $a_{1}$ " of pressure increase in the regulator $a_{1}=0$ ); the series throttling control assembly in the form of:

1. servo-valve, 2. proportional directional valve, 3. set throttling valve, 4. set two-way flow regulator 
because the current pump capacity $\mathrm{Q}_{\mathrm{p}}$ is adjusted, by the LS regulator, to the current flow intensity $\mathrm{Q}_{M}$ set by the throttling assembly (i.e. $\mathrm{Q}_{\mathrm{P}}=\mathrm{Q}_{\mathrm{M}}$ ).

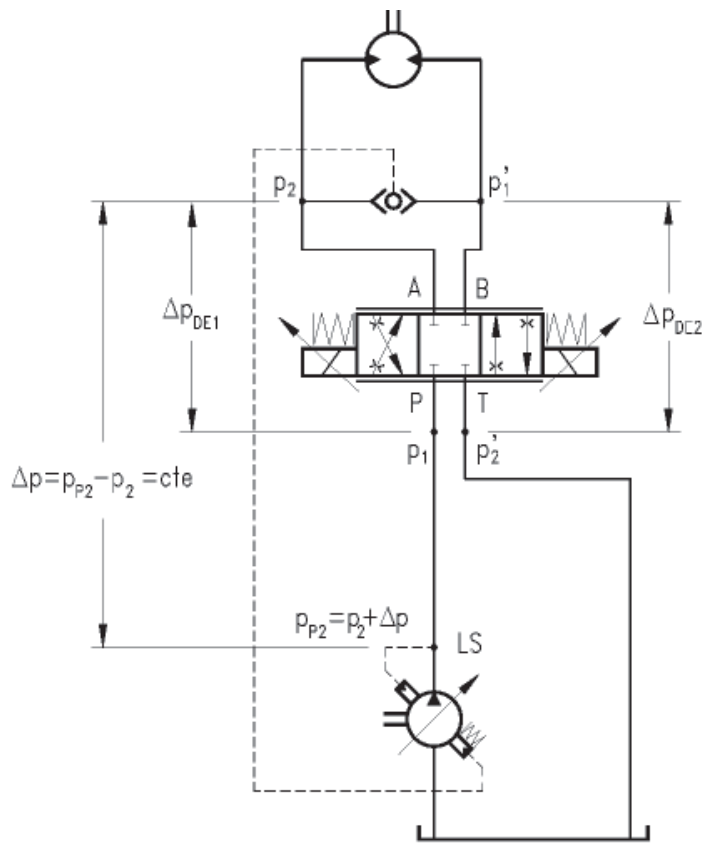

Fig. 12. Individual system with rotational hydraulic motor speed series throttling control fed by a variable capacity pump cooperating with Load

Sensing regulator in the variable pressure conditions $p_{P 2}=$ var; the throttling control assembly in the form of servo-valve or proportional directional valve

Pressure $\mathrm{p}_{\mathrm{P} 2}$ of the pump operation, adjusted by the LS regulator, is, as in the series throttling control assembly feeding system with the constant capacity pump cooperating with an SPS variable pressure overflow valve (Fig. 6), set at a level higher by the value of $\Delta \mathrm{p}_{\mathrm{LS}}=\Delta \mathrm{p}_{\mathrm{DE} 1 \mid \mathrm{f}_{\mathrm{DE} \text { max }}, \mathrm{Q}_{\mathrm{Pt}}}+\Delta \mathrm{p}_{\mathrm{Clmax}}=$ cte than the current pressure $\mathrm{p}_{2}$ in the throttling proportional control valve outlet conduit to the hydraulic motor. The value $\Delta \mathrm{p}_{\mathrm{LS}}=\mathrm{p}_{\mathrm{P} 2}-\mathrm{p}_{2}$ of the pressure difference must allow to obtain, through the throttling proportional valve slot DE1 (controlling the flow intensity $\mathrm{Q}_{\mathrm{M}}$ feeding the hydraulic motor), the flow intensity $\mathrm{Q}_{\mathrm{M}}$ equal to DE1 slot area reaches then the maximum size $\mathrm{f}_{\mathrm{DEI} \max }$ and a possibility of pressure decrease $\Delta \mathrm{p}_{\mathrm{LS}}=$ $=\Delta \mathrm{p}_{\mathrm{DE} 1 \mid \mathrm{f}_{\mathrm{DElmax}}, \mathrm{Q}_{\mathrm{Pt}}}$ required by the throttling proportional design, with simultaneous capability of overcoming the maximum flow resistance value $\Delta \mathrm{p}_{\mathrm{Clmax}}$ which may occur in the conduit between the pump and the directional valve.

Like in the series throttling control system fed by the constant capacity pump cooperating with a variable pressure overflow valve SPS, the current value of the pump discharge pressure $\mathrm{p}_{\mathrm{P} 2}$, higher by a value of $\Delta \mathrm{p}_{\mathrm{LS}}$ then the current pressure value $p_{2}$ at the throttling proportional directional valve outlet to the hydraulic motor, adjusts itself to the pressure value $\mathrm{p}_{\mathrm{M} 1}$ required by the motor at its inlet. The maximum limit pressure value $\mathrm{p}_{\mathrm{P} 2 \max }$ in the pump discharge conduit also here is determined by the overflow valve SP, whose opening pressure $\mathrm{p}_{\mathrm{SP} 0}$ is equal to the system nominal pressure $\mathrm{p}_{\mathrm{n}}$.

Therefore, in the hydraulic motor speed series throttling control assembly Load Sensing feeding system, the power $\Delta \mathrm{P}_{\mathrm{stp}}=\Delta \mathrm{p}_{\mathrm{DE}} \mathrm{Q}_{\mathrm{M}}$ of structural pressure losses occurring in the throttling control assembly during loading the hydraulic motor with a smaller torque will be considerably reduced (compared with the situation in a system fed by a variable capacity pump with a pressure regulator $p=$ cte $\approx p_{n}$ (Fig. 3)). With a simultaneous elimination of the power $\Delta \mathrm{P}_{\text {stv }}$ of the structural volumetric losses in the throttling control assembly, the LS system allows to decrease to a negligible value the sum of power $\Delta \mathrm{P}_{\mathrm{st}}$ of structural energy losses resulting from the use of series throttling as a form of precise hydraulic motor speed control.

In a rotational hydraulic motor operating in an LS system, practically the same three values of power of energy losses $\left(\Delta \mathrm{P}_{\mathrm{Mm}}, \Delta \mathrm{P}_{\mathrm{Mv}}\right.$ and $\left.\Delta \mathrm{P}_{\mathrm{Mp}}\right)$ occur as in the above mentioned systems (with a tendency to slight decrease of the power $\Delta \mathrm{P}_{\mathrm{Mm}}$ of mechanical losses and power $\Delta \mathrm{P}_{\mathrm{Mv}}$ of volumetric losses in the motor operating in a $\mathrm{p}=$ var system, in this case in the LS system).

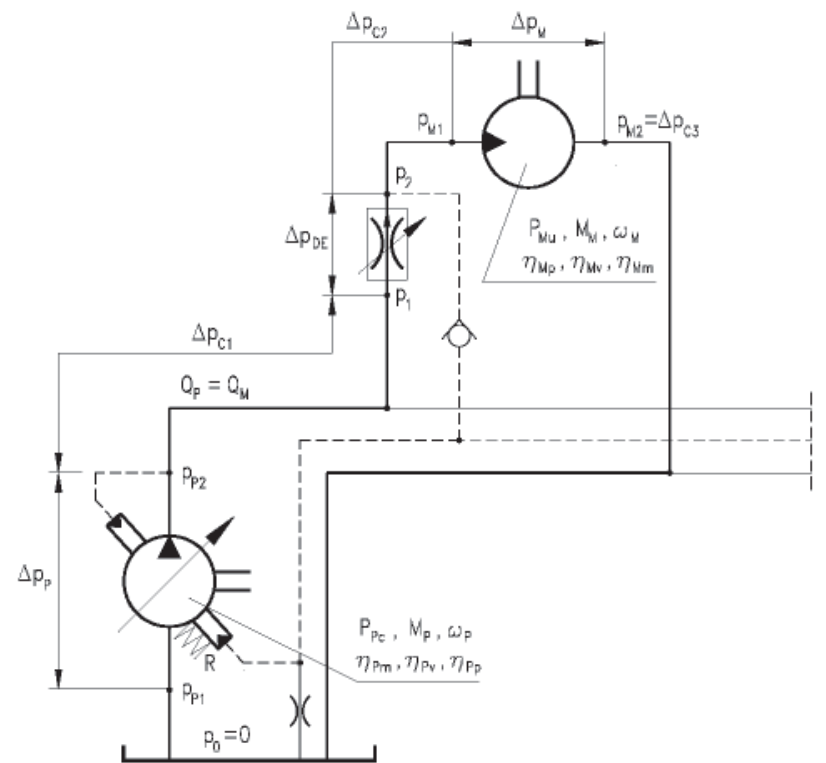

Fig. 13. Central system with parallelly situated motors and with variable capacity pump cooperating with Load Sensing regulator in the variable pressure conditions $p_{P 2}=v a r-$ during one motor operation

Power $\Delta \mathrm{P}_{\mathrm{C}}=\Delta \mathrm{p}_{\mathrm{C}} \mathrm{Q}_{\mathrm{M}}$ of the pressure losses in the conduits of a system with LS feeding of the throttling control assembly remains unchanged at a given motor speed $\omega_{M}\left(n_{M}\right)$, i.e. equal to the $\Delta \mathrm{P}_{\mathrm{C}}$ values in the above mentioned systems.

In a variable capacity pump cooperating with a Load Sensing regulator of the variable pressure $(p=$ var) feeding system of a hydraulic motor series throttling speed control assembly occurs (compared with three above mentioned series throttling control systems and with unchanged useful power $\mathrm{P}_{\mathrm{Mu}}=\mathrm{M}_{\mathrm{M}} \omega_{\mathrm{M}}$ of the motor) decrease of the power $\Delta \mathrm{P}_{\mathrm{Pp}}=\Delta \mathrm{p}_{\mathrm{Pp}}$ $\mathrm{Q}_{\mathrm{P}}$ of pressure losses in the pump (due to decrease of $\mathrm{Q}_{\mathrm{P}}$ and $\Delta \mathrm{p}_{\mathrm{Pp}}$ ), decrease of the power $\Delta \mathrm{P}_{\mathrm{Pv}}=\Delta \mathrm{p}_{\mathrm{Pi}_{\mathrm{i}}} \mathrm{Q}_{\mathrm{Pv}}$ of volumetric losses in the pump (due to decrease of $\Delta \mathrm{p}_{\mathrm{P}_{\mathrm{i}}}$ and $\mathrm{Q}_{\mathrm{P}_{\mathrm{v}}}$ ) and decrease of power $\Delta \mathrm{P}_{\mathrm{Pm}}=\mathrm{M}_{\mathrm{Pm}} \omega_{\mathrm{P}}$ of mechanical losses in the pump (due to decrease of $\mathrm{M}_{\mathrm{Pm}}$ with slight increase of $\omega_{\mathrm{P}}$ ).

The use, as a feeding source of the hydraulic motor series throttling speed control system, of a variable capacity pump with the Load Sensing regulator operating at a pressure $\mathrm{p}_{\mathrm{P} 2}=$ $=\Delta \mathrm{p}_{\mathrm{LS}}+\mathrm{p}_{2} \approx \Delta \mathrm{p}_{\mathrm{LS}}+\mathrm{p}_{\mathrm{M} 1}$, i.e. slightly higher then the current pressure $\mathrm{p}_{\mathrm{M} 1}$ required by the hydraulic motor at its inlet (which is accompanied by decrease to a small value of the power $\Delta \mathrm{P}_{\text {st }}$ of structural energy losses in the throttling control assembly), reduces the sum of power of energy losses in the system to a value only slightly higher then the sum of power of losses in the elements of a system with volumetric control of the motor speed (directly by a variable pump capacity). Power $\mathrm{P}_{\mathrm{Pc}_{\mathrm{c}}}=$ $=\mathrm{M}_{\mathrm{p}} \omega_{\mathrm{p}}$ absorbed by the pump from the electric or internal combustion drive motor is only slightly higher here then the power $\mathrm{P}_{\mathrm{Pc}}$ of a variable capacity pump directly driving the hydraulic motor.

The considered LS system operates in the whole range $0 \leq \mathrm{M}_{\mathrm{M}} \leq \mathrm{M}_{\mathrm{M} \max }$ of the hydraulic umotor load and in the whole 
range $0 \leq \omega_{\mathrm{M}} \leq \omega_{\mathrm{Mmax}}$ of its speed with the energy efficiency $\eta$ only slightly lower then the efficiency $\eta$ of a volumetric control system (directly by a variable capacity pump). The difference between overall efficiencies $\eta$ of both systems will be inversely dependent on the capability of increase of the area of throttling proportional valve (or throttling valve) slot $\mathrm{f}_{\text {DEmax }}$. The increase of $\mathrm{f}_{\text {DEmax }}$ allows to decrease $\Delta \mathrm{p}_{\text {DEmin }} \approx 0$ at a maximum flow intensity $\mathrm{Q}_{\mathrm{M} \max }=\mathrm{Q}_{\mathrm{P} \max }$ (i.e. equal to a full pump capacity). It also requires correct operation of the pump LS regulator adjusting, in the whole range $0 \leq Q_{p} \leq Q_{M \max }$ of the pump capacity, the discharge pressure $\mathrm{p}_{\mathrm{P} 2}$ at the level higher by a value $\Delta \mathrm{p}_{\mathrm{LS}}=\mathrm{p}_{\mathrm{P} 2}-\mathrm{p}_{2}=$ cte then the $\mathrm{p}_{2}$ pressure in the discharge conduit from the throttling proportional control valve (throttling valve) to the hydraulic motor.

\section{To be continued in the next issue}

\section{BIBLIOGRAPHY}

1. Paszota Z.: Aspects énergétiques des transmissions hydrostatiques, Monograph, 2002

2. Paszota Z.: Model of losses and efficiency of an energy - saving hydraulic servomechanism system, Marine Technology Transactions, Polish Academy of Sciences, Branch in Gdansk, Vol. 18, 2007

3. Paszota Z.: Energy saving in a hydraulic servomechanism system, Proc. $17^{\text {th }}$ Symposium on Theory and Practice of Shipbuilding in memoriam prof. Leopold Sorta, Opatija, 19-21 October 2006

4. Skorek G.: Energy characteristics of the hydraulic systems with proportionally controlled cylinder fed in a constant or variable pressure (in Polish), Doctor dissertation, Gdansk University of Technology, continuation

5. Paszota Z.: Energy Saving in a Hydraulic Servomechanism System - Theory and Examples of Laboratory Verification, Brodogradnja, Journal of Naval Architecture and Shipbuilding Industry, Vol. 58, No 2, Zagreb, June 2007

6. Paszota Z.: Hydraulic Servomechanism System. Examples of Reduction of Power Losses in the Variable Pressure Power Supply, International Scientific - Technical Conference "Hydraulics and Pneumatics'2007", Wrocław, 10 - 12 October 2007

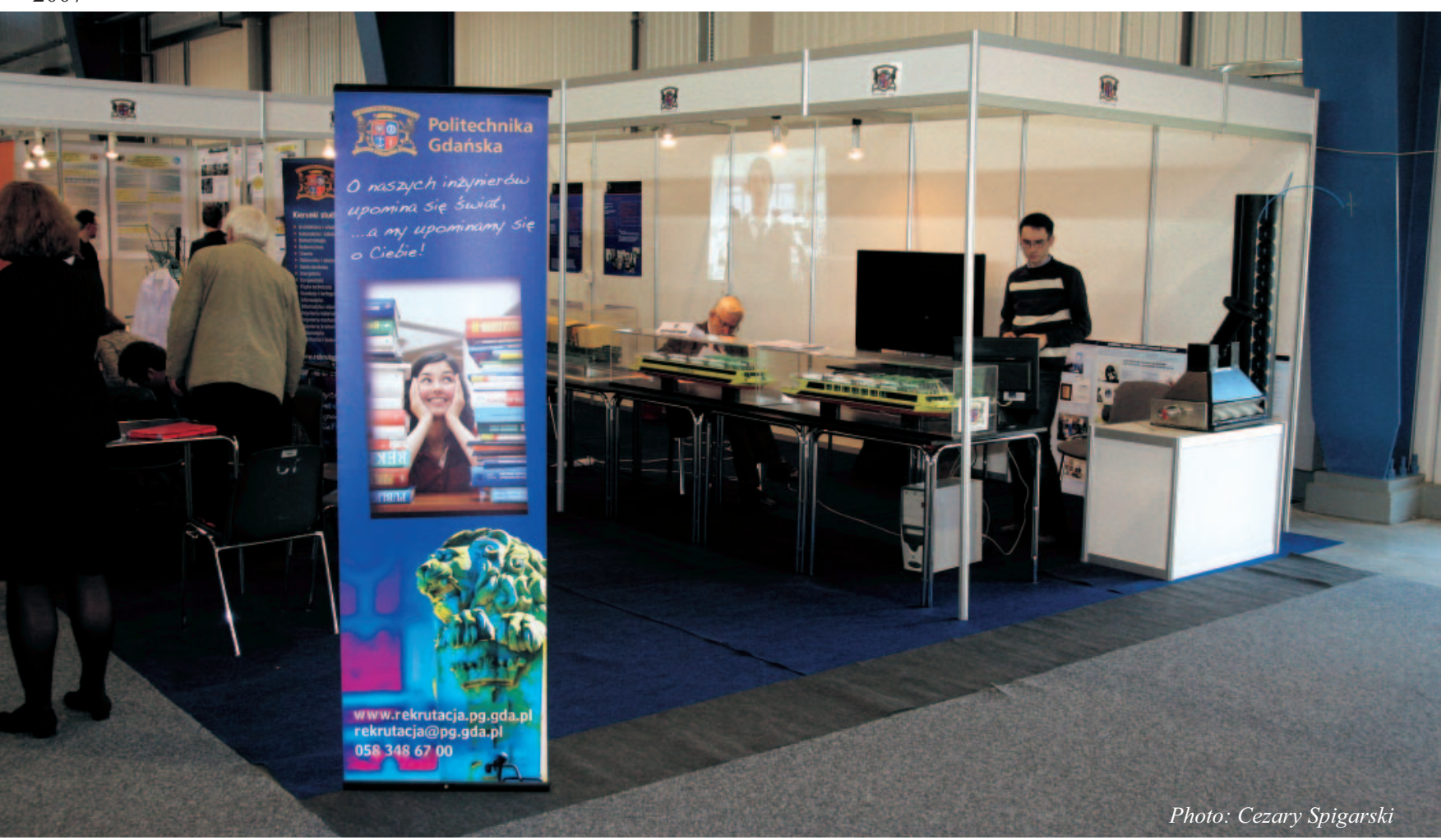

7. Paszota Z.: Power of energy losses in the hydrostatic drive system elements - definitions, relations, range of changes, energy efficiencies. Part I - Hydraulic motor. Chapter in the hydraulic systems" (in Polish), Andrzej Meder and Adam Klich editors. „Cylinder” Library. Komag Mining Mechanisation Centre, Gliwice 2007

8. Paszota Z.: Power of energy losses in the hydrostatic drive system elements - definitions, relations, range of changes, energy efficiencies. Part II - Conduits, throttling control assembly, pump. Chapter in the monograph: „Research, design, production and operation of hydraulic systems" (in Polish), Andrzej Meder and Adam Klich editors. „Cylinder” Library. Komag Mining Mechanisation Centre, Gliwice 2007

9. Paszota Z.: Power of energy losses in the hydrostatic drive system elements - definitions, relations, range of changes, energy efficiencies (in Polish). Part I - Hydraulic motor. Napędy i sterowanie, scientific monthly, No 11 (103), November 2007

10.Paszota Z.: Power of energy losses in the hydrostatic drive system elements - definitions, relations, range of changes, energy efficiencies (in Polish). Part II - Conduits, throttling monthly, No 12 (104), December 2007

11.Paszota Z.: Graphical presentation of the power of energy losses and power developed in the elements of hydrostatic drive and control system (in Polish). Part I - Rotational hydraulic motor speed series throttling control systems. To be presented at the Cylinder'2008 Conference in September 2008

12.Paszota Z.: Graphical presentation of the power of energy losses and power developed in the elements of hydrostatic drive and control system (in Polish). Part II - Rotational hydraulic motor speed parallel throttling control and volumetric control systems. To be presented at the Cylinder'2008 Conference in September 2008

\section{CONTACT WITH THE AUTHOR}

Prof. Zygmunt Paszota

Faculty of Ocean Engineering and Ship Technology

Gdansk University of Technology

Narutowicza 11/12

80-952 Gdansk, POLAND

e-mail: zpaszota@pg.gda.pl monograph: ,Research, design, production and operation of control assembly, pump. Napędy i sterowanie, scientific 